\title{
The Journal of Neurology, Neurosurgery and Psychiatry centenary milestone award 2020
}

\author{
Matthew C Kiernan ${ }^{1,2}$
}

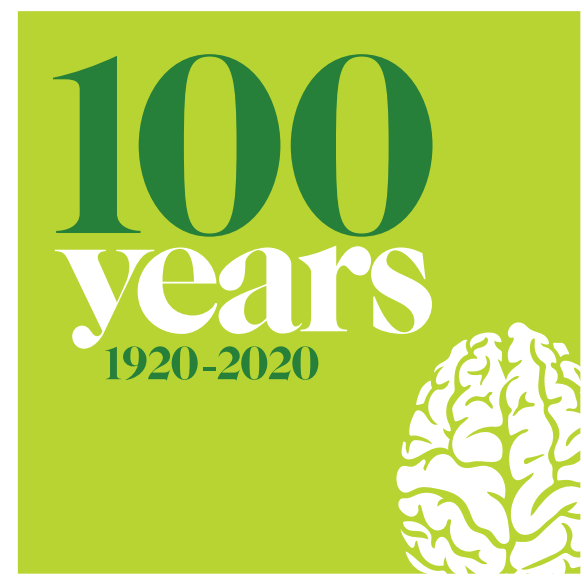

JNNP 2020-a centenary of publishing neuroscience achievement

Late last year, the Journal of Neurology, Neurosurgery and Psychiatry (JNNP) polled readers, asking them to nominate the single most important or transformative development in neurology, neurosurgery or psychiatry in the past 100 years. The response was overwhelming!

Would the early foundational work in brain imaging or drug therapies ${ }^{1-4}$ take centre stage? Did the phenomenal advancements in genetic research ${ }^{5-7}$ or the discovery of new biological pathways ${ }^{8}$ make the grade? Perhaps the discovery of ion channels, the role of neuroinflammation and the advent of autoimmune disease ${ }^{9-11}$ ? Or was the groundbreaking work in stroke or mental health ${ }^{12-15}$ going to steal the show? We left the answer entirely to our readers-the colleagues and collaborators, researchers and clinicians who contribute to and benefit from these breakthroughs in their everyday work.

During the most recent end-of-year meeting hosted by JNNP editors and its publisher BMJ, the most worthy of those trail-blazing nominations were shortlisted. The finalists are as follows, in no specific order:

\footnotetext{
'Bushell Chair of Neurology, Brain and Mind Centre, University of Sydney, Sydney, New South Wales, Australia

${ }^{2}$ Neurology, Royal Prince Alfred Hospital, Camperdown, New South Wales, Australia
}

Correspondence to Professor Matthew C Kiernan, Bushell Chair of Neurology, Brain and Mind Centre, University of Sydney, Sydney, NSW 2006, Australia; matthew.kiernan@sydney.edu.au
Brain imaging-The development and application of imaging techniques.

Parkinson's disease-The efficacy of L-Dopa therapy.

Multiple sclerosis-The evolution of new therapy.

Neurosurgery-The advent of deep brain stimulation.

Neurogenetics-The discovery of causal genes.

Stroke-The introduction of thrombolysis and endovascular recanalisation therapy.

Neurotransmission-The discovery of ion channels and the electrical properties of axons. Neuropsychiatry-The introduction of therapies.

Neurosurgery-The introduction of the microscope and microsurgical techniques. Autoimmune disease-Unlocking disease pathophysiology; introduction of novel therapies.

Regardless of your field of expertise, we are now asking our readers to weigh the merits of each nomination and choose their number one.

With voting closing in late July, the editors will convene centenary celebrations at BMA House, London, in September, at which time presentations of the shortlisted topics will take place. It is here that the JNNP Editorial Board will cast a final vote and announce the winner.

So, please vote now at (http://bit.ly/ 2unexPH) to nominate what you consider the greatest breakthrough in clinical neuroscience since 1920 and join us to celebrate JNNP's role in a remarkable century of neuroscientific achievement.

Funding The authors have not declared a specific grant for this research from any funding agency in the public, commercial or not-for-profit sectors.

Competing interests None declared.

Patient consent for publication Not required.

Provenance and peer review Commissioned; internally peer reviewed.

(C) Author(s) (or their employer(s)) 2020. No commercial re-use. See rights and permissions. Published by BMJ.

D Check for updates

To cite Kiernan MC. J Neurol Neurosurg Psychiatry 2020;91:677.

Received 6 February 2020

Accepted 6 February 2020
Published Online First 2 March 2020

J Neurol Neurosurg Psychiatry 2020;91:677.

doi:10.1136/jnnp-2020-322976

\section{REFERENCES}

1 O'Brien JT, Firbank MJ, Ritchie K, et al. Association between midlife dementia risk factors and longitudinal brain atrophy: the PREVENT-Dementia study. J Neurol Neurosurg Psychiatry 2020;91:158-61.

2 González HFJ, Chakravorti S, Goodale SE, et al. Thalamic arousal network disturbances in temporal lobe epilepsy and improvement after surgery. J Neurol Neurosurg Psychiatry 2019;90:1109-16.

3 Juryńczyk M, Tackley G, Kong Y, et al. Brain lesion distribution criteria distinguish MS from AQP4antibody NMOSD and MOG-antibody disease. J Neurol Neurosurg Psychiatry 2017;88:132-6.

4 Lunde HMB, Assmus J, Myhr K-M, et al. Survival and cause of death in multiple sclerosis: a 60-year longitudinal population study. J Neurol Neurosurg Psychiatry 2017;88:621-5.

5 Ferrari R, Wang Y, Vandrovcova J, et al. Genetic architecture of sporadic frontotemporal dementia and overlap with Alzheimer's and Parkinson's diseases. J Neurol Neurosurg Psychiatry 2017;88:152-64.

6 Previtali SC, Zhao E, Lazarevic D, et al. Expanding the spectrum of genes responsible for hereditary motor neuropathies. J Neurol Neurosurg Psychiatry 2019;90:1171-9.

7 Zou Z-Y, Zhou Z-R, Che C-H, et al. Genetic epidemiology of amyotrophic lateral sclerosis: a systematic review and meta-analysis. J Neurol Neurosurg Psychiatry 2017;88:540-9.

8 Eisen A, Braak H, Del Tredici K, et al. Cortical influences drive amyotrophic lateral sclerosis. J Neurol Neurosurg Psychiatry 2017;88:917-24.

9 Lang B, Makuch M, Moloney T, et al. Intracellular and non-neuronal targets of voltage-gated potassium channel complex antibodies. J Neurol Neurosurg Psychiatry 2017;88:353-61.

10 Kawachi I, Lassmann H. Neurodegeneration in multiple sclerosis and neuromyelitis optica. J Neurol Neurosurg Psychiatry 2017;88:137-45.

11 Stellmann J-P, Krumbholz M, Friede T, et al. Immunotherapies in neuromyelitis optica spectrum disorder: efficacy and predictors of response. J Neurol Neurosurg Psychiatry 2017;88:639-47.

12 Muir KW, Ford GA, Messow C-M, et al. Endovascular therapy for acute ischaemic stroke: the pragmatic ischaemic stroke thrombectomy evaluation (PISTE) randomised, controlled trial. J Neurol Neurosurg Psychiatry 2017;88:38-44.

13 Nielsen G, Buszewicz M, Stevenson F, et al. Randomised feasibility study of physiotherapy for patients with functional motor symptoms. J Neurol Neurosurg Psychiatry 2017;88:484-90.

14 Robinson OJ, Pike AC, Cornwell B, et al. The translational neural circuitry of anxiety. J Neurol Neurosurg Psychiatry 2019;90:1353-60.

15 Simpson R, Simpson S, Ramparsad N, et al. Mindfulness-based interventions for mental well-being among people with multiple sclerosis: a systematic review and meta-analysis of randomised controlled trials. J Neurol Neurosurg Psychiatry 2019;90:1051-8. 